Postgraduate Medical Journal (November 1982) 58, 716-719

\title{
Subcutaneous nodular synovitis following medial arthrotomy in a case of myxoid liposarcoma of the thigh
}

\author{
J. MCCLURE \\ B.Sc., M.D., D.M.J.Path., M.R.C.Path. \\ R. J. BAUZE \\ PREMA IYER \\ M.B., B.S., F.R.C.P.A. \\ M.B., B.S., F.R.A.C.S. \\ T. MUKHERJEE \\ M.B., B.S., D.G.O., M.D. \\ The Adelaide Bone and Joint Research Unit and the Division of Tissue Pathology IMVS, Frome Road, Adelaide, \\ South Australia
}

\begin{abstract}
Summary
A lesion of pigmented synovitis appeared as a nodule in the scar one year after arthrotomy and was removed one year later. It was clearly distinguished from a concurrent myxoid liposarcoma on clinical and morphological grounds (light and electron microscopy).
\end{abstract}

\section{Introduction}

Pigmented synovitis is a well defined disorder affecting joints, tendons and bursae in a diffuse or nodular form. A variety of names reflect site and morbid anatomy: giant cell tumour of tendon sheath, localized nodular synovitis (Granowitz and Mankin, 1967; Fraire and Fechner, 1972) and pigmented villonodular synovitis (Jaffe, Lichtenstein and Sutro, 1941). Aetiology and pathogenesis are unknown, but all recognize the lesions to be similar, to be reactive, and very probably to result from repeated haemorrhage. The changes in the synovium of haemophiliacs are most often adduced in support of this argument. We record this very unusual case of a subcutaneous pigmented lesion, arising one year after arthrotomy, examined by light and electron microscopy, to add to experience and knowledge of this uncommon condition. We believe the lesion to have developed in displaced synovium. Difficulty and interest was added by a concurrent liposarcoma.

\section{Case report}

A 28-year-old man injured his left knee. After several months of persistent pain and swelling, with episodic collapsing and clicking, a torn left lateral meniscus was removed. Recovery was uneventful.

Requests for reprints to: Dr J. McClure, C/- IMVS, Box 14, Rundle Street Post Office, Adelaide, South Australia 5001.
One year later he twisted his right knee. He presented himself after 14 months because of persisting symptoms. During the last 2 months he had also noticed a lump on the inner side of his right lower thigh, which was confirmed by clinical examination. Plain X-rays of the knee were normal. A medial arthrotomy was performed; there was no abnormality of the meniscus or synovium. The arthrotomy wound was closed using 3 figure-of-eight vicryl sutures closing the synovium and capsule in one layer. A continuous vicryl suture was placed in the subcutaneous tissue and the skin was closed by a sub-cuticular prolene suture. The back of the knee was then explored: there was a multilobulated, well-encapsulated tumour $100 \times 40 \mathrm{~mm}$ beneath the adductor magnus muscle belly.

Recovery was uneventful, but he continued to have pain in his knee. Three months after the last operation a torn lateral meniscus was removed. The synovium was normal.

One year later a $3 \mathrm{~mm}$, mobile, painless lump was noted in the lower end of the medial arthrotomy wound of the right knee, attached to the capsule but not to the skin. A suture granuloma was diagnosed. One year later it was slightly painful, $10 \mathrm{~mm}$ in diameter and fairly mobile. The lump plus an ellipse of subcutaneous tissue and skin were excised. There was a smaller ( $3 \mathrm{~mm}$ diameter) nodule just beneath the capsule in the line of the wound. This was also excised together with a segment of capsule. The wound healed well and recovery has been uneventful.

\section{Pathological findings}

The tumour from the back of the right knee exhibited the features of a myxoid variant of liposarcoma (Fig. 1). Lobulated and yellow-pink in colour, 


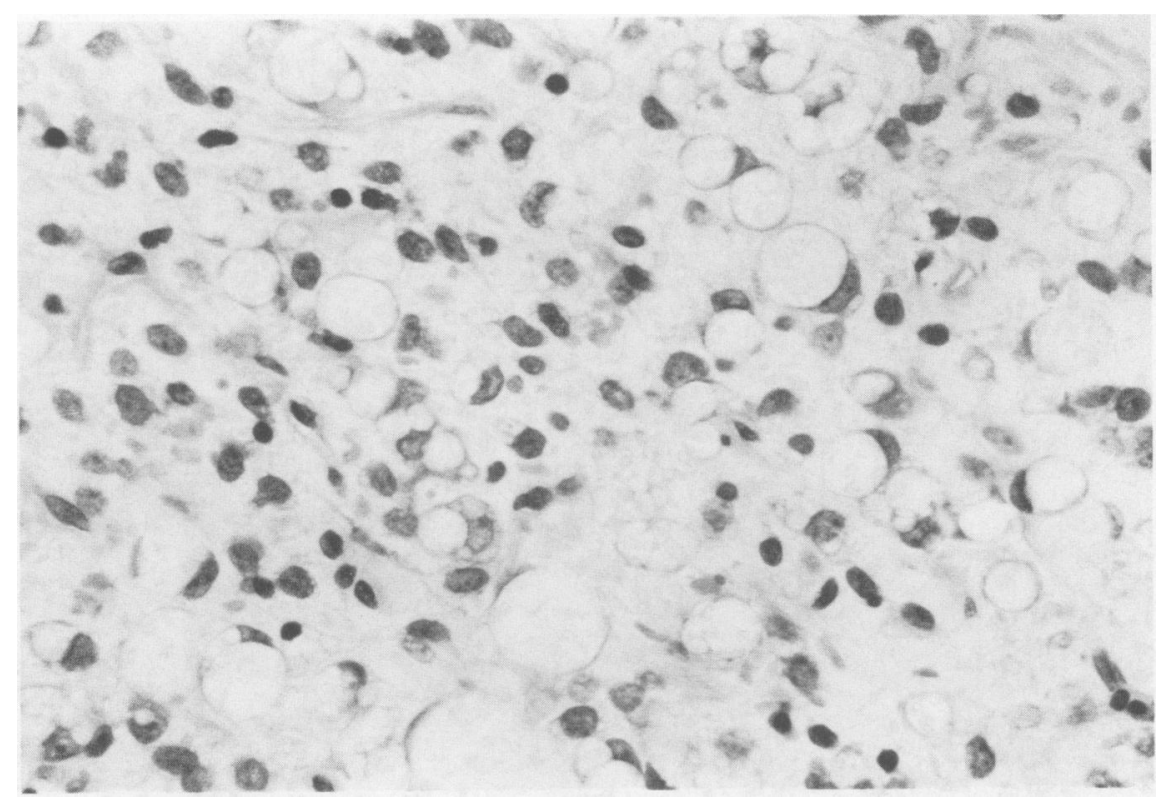

FIG. 1. There are numerous lipoblasts with pleomorphic nuclei and lipidic droplets of variable size in this myxoid variant of liposarcoma. H.E $\times \mathbf{4 0 0}$.

it was cellular, myxoid and vascular. The tumour cells had oval and stellate nuclei, pale cytoplasm and indistinct margins. Nuclear pleomorphism was mild and mitoses were sparse. There were proliferating lipoblasts in various stages of differentiation and large multivacuolated forms. The capillaries formed a delicate plexiform pattern. Hyaluronidase-sensitive acid mucopolysaccharides were demonstrated.

Skin and subcutaneous tissues with a nodule in the latter and a portion of joint capsule with an attached smaller nodule were received from the second operation. Both nodules had brown cut surfaces and were identical microscopically. Septae of dense collagen demarcated cellular areas with mononuclear cells, multinucleated giant cells and small numbers of foam cells (Fig. 2). Haemosiderin was abundant. The features were identical to those of a nodular (teno) synovitis. Neither foreign material, nor acid and/or alcohol fast organisms nor fungi were found.

Tissue enucleated from paraffin blocks was processed in the conventional manner for transmission electron microscopy (TEM). The sections stained with uranyl acetate and lead citrate were examined in a JEM $100 \mathrm{CX}$ electron microscope. Four types of cell were identified. One conformed to the description by Alguacil-Garcia, Krishnan and Goellner (1978) and Eisenstein (1968) of the type A synoviocyte. This had a highly electron dense cytoplasm, abundant cytoplasmic filopodia, a high concentration of mitochondria, a poorly developed rough endoplasmic reticulum (RER) (Fig. 3) and a few lysosomes. The nuclei were either oval or elongated and occasional cells were binucleated. The distinguishing feature of these cells was the presence of a prominent nucleolus. The second type of cell was the type $B$ synoviocyte of the above authors, portions of which may be seen in Figure 3.

The cytoplasm was pale with well developed but sparse RER, usually with dilated cisternae and comparatively few mitochondria. Very often the nucleus was highly indented with an inconspicuous nucleolus. Junctional complexes were seen between both types of cell and often the type $B$ cells were surrounded either wholly or in part by basal laminar material. Insinuations of collagen fibrils were also seen between both cell types. Haemosiderin granules, characteristically present in type B cells, were also seen in some type A cells. Type A and type B cells were by far the commonest of all cell types.

The third cell type was the multinucleated giant cell, consisting of voluminous cytoplasm, crowded with mitochondria, strips of RER and vesicles containing electron dense inclusions. The number of nuclei varied greatly and some showed prominent nucleoli, a feature consistently seen in type A cells. Although they were surrounded by both type $A$ and type $B$ cells the association between the giant cells 


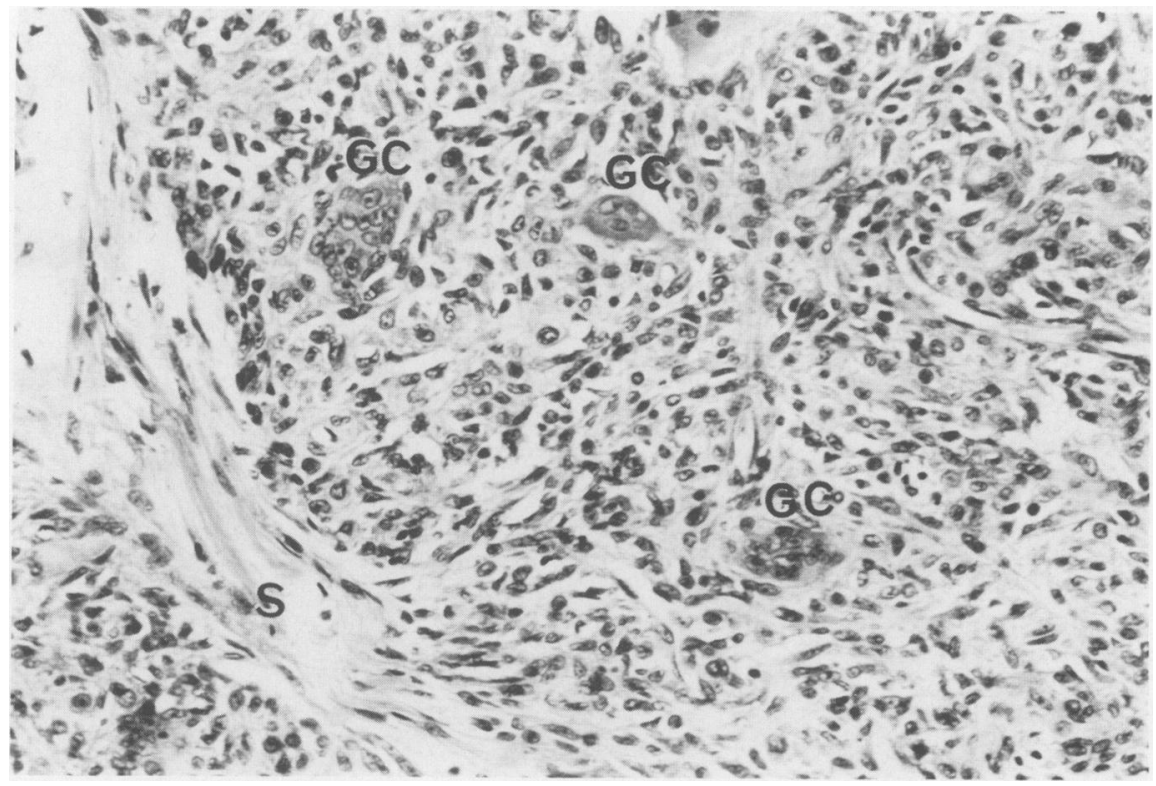

FIG. 2. The nodular lesions are divided into lobules bounded by fibrous septae (S) and contain giant cells (GC) and mononuclear cells. H.E $\times 200$.

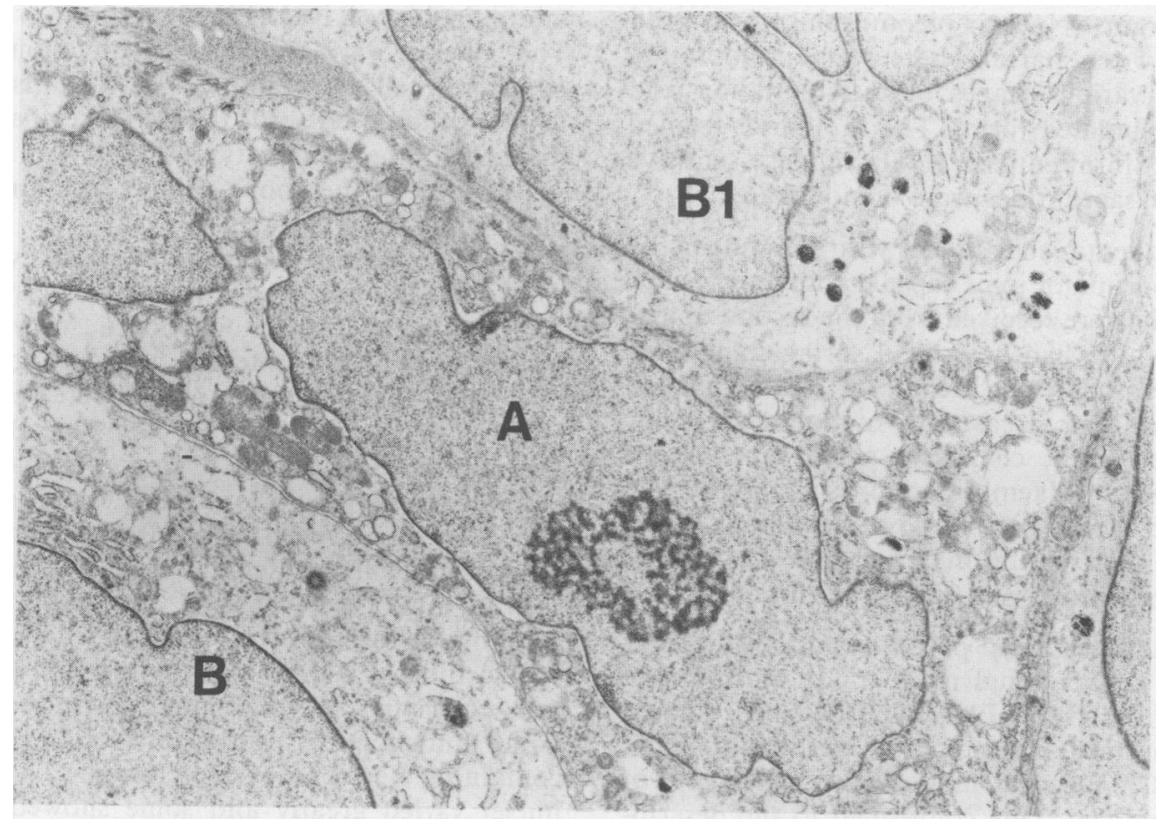

Fig. 3. Both type A and type B cells are illustrated. The centrally placed A cell has dense cytoplasm, a concentration of mitochondria and a fusiform nucleus. Portions of type B cells (marked B and B1) are present on either side of the type A cell. These demonstrate pale cytoplasm, well developed but sparse RER (rough endoplasmic reticulum) and haemosiderin granules. Magnification $\times 8700$. 
and the type A cells was more intimate since type B cells were invariably separated from the giant cells by a thin basal lamina and/or collagen fibrils. Occasionally giant cells surrounded type A cells; the suggestion that there was incorporation was enhanced by the breaking down of plasma membranes which separated them. In addition, continuity of cytoplasm between a type A cell and a giant cell was found.

The fourth cell was a typical fibroblast seen mostly in the septae. These differed from the fusiform type $A$ cell: they contained only moderate amounts of RER, had no concentration of mitochondria and cytoplasm was less dense. Furthermore they were surrounded by bundles of well formed collagen.

\section{Discussion}

The interest of this case lies in the occurrence of subcutaneous, extracapsular proliferative lesions at the site of a previous arthrotomy of the right knee. Extrinsic foreign body material and infection by mycobacteria or fungi were excluded as causes. The appearances were identical on light and electron microscopy to pigmented synovitis, whether the common nodular tenosynovitis (so-called giant cell tumour of tendon sheaths) or the very much less common intra-articular localized nodular synovitis.

Jaffe et al. (1941) collected a group of synovial lesions of similar appearance, named xanthoma, xanthogranuloma, giant cell fibrohaemangioma and synovioma of joints, bursae and tendon sheaths. They gave them the descriptive title of pigmented villo-nodular synovitis (PVNS). Jaffe and his colleagues recognized that the intra-articular lesion could be localized or diffuse but both were considered manifestations of a common pathological process; a reactive proliferation of synoviocytes. This view was supported by Lichtenstein (1955) and more recently by Eisenstein (1968) with ultrastructural evidence. The diffuse variant of PVNS may cause erosion of articular cartilage and bone and infiltrate the latter (McMaster, 1960). Local infiltrative behaviour has not been described for localized nodular synovitis.

There was no evidence of pigmented synovitis at either operation on the right knee, and no grounds exist for thinking that the lesions reported here arose from within the joint by infiltration. Therefore, one can only speculate that the previous arthrotomy caused a displacement of synovial tissue from which proliferation arose. The factors responsible for initiating this proliferation are mysterious, particularly in view of the fact that arthrotomy had been performed in an identical fashion in numerous other cases without a similar consequence.

Despite the processing of paraffin blocks, cellular preservation was sufficient for ultrastructural identification of type $A$ and Type B synoviocytes described by Alguacil-Garcia et al. (1978) and Eisenstein (1968) in their studies of nodular tenosynovitis. They observed many mitochondria, electron-dense cytoplasm and cytoplasmic filopodia in type A synoviocytes, whereas pale cytoplasm, well developed RER with dilated cisternae and haemosiderin granules were the features of type B synoviocytes. Eisenstein's (1968) proposal that the multinucleated giant cells of nodular tenosynovitis are formed by the fusion of type A synoviocytes is supported by observations in the present studies.

The possiblity that the subcutaneous lesions were deposits from the myxoid liposarcoma was seriously considered clinically, but no continuity was ever observed. The dissimilar macroscopic and histological appearances of these two lesions can hardly be confused. Nevertheless we examined the possibility closely. Feldman (1979) has described the ultrastructural features of myxoid liposarcoma. A prominent feature was extensive lipid droplets in the cytoplasm of the lipoblasts. In the present case only small numbers of foam cells were seen by light microscopy and occasional cytoplasmic vacuoles were seen in the fibroblasts by electron microscopy. Neither extensive vacuoles nor other features of lipoblasts, as observed by Feldman (1979) were found in any of the synoviocytes.

\section{References}

AlguaCil-Garcia, A., Krishnan, K.U. \& Goellner, J.R. (1978) Giant cell tumour of tendon sheath and pigmented villo-nodular synovitis. An ultrastructural study. American Journal of Clinical Pathology, 69, 6.

EISENSTEIN, R. (1968) Giant cell tumour of tendon sheath. Its histogenesis as studied in the electron microscope. Journal of Bone and Joint Surgery, 50A, 476.

FELDMAN, P.S. (1979) A comparative study including ultrastructure of intramuscular myxoma and myxoid liposarcoma. Cancer (Philadelphia), 43, 512.

FRAIRE, A.E. \& FECHNER, R.E. (1972) Intra-articular localised nodular synovitis of the knee. Archives of Pathology, 93, 473.

GRANOWITZ, S.P. \& MANKIN, H.J. (1967) Localised pigmented villo-nodular synovitis of the knee. Journal of Bone and Joint Surgery, 49A, 122.

JafFe, H.L., Lichtenstein, L. \& Sutro, C.I. (1941) Pigmented villo-nodular synovitis, bursitis and tenosynovitis. Archives of Pathology, 31, 731.

LiCHTENSTEIN, L. (1955) Tumours of synovial joints, bursae and tendon sheaths. Cancer (Philadelphia), 8, 816.

MCMaster, P.E. (1960) Pigmented villo-nodular synovitis with invasion of bone. Report of six cases. Journal of Bone and Joint Surgery, 42A, 1170. 